\title{
To assess the ergonomic hazards and related musculoskeletal discomfort among bank employees
}

\section{Neha Arya and Seema Kwatra}

Received: 23.02.2019; Revised: 02.10.2019; Accepted: 16.10 .2019

See end of the paper for authors' affiliations Neha Arya

Department of Family Resource Management, College of Home Science, G.B. Pant University of Agriculture and Technology, Pantnagar, Udham Singh Nagar (Uttarakhand) India

Email : nehaarya.arya6@ gmail.com
ABSTRACT : Banking sector is the backbone of the nation and lifeline for its people. In banks, work load is very high, so new advancements in computers, made their work and life easier and faster, increased their work efficiency and saved time. Despite feeling relaxed with modern technology in the banking sector, employees feel overloaded with work and stressed out to cope with those changes resulting in increased health related hazards. The results revealed that computer workstation used by bank employees was not appropriate and employees had to adjust to fixed design features at work. Musculoskeletal pain /discomfort was emerged among bank employees due to long working hours, awkward body postures and repetitive work. Approximately thirty per cent of the employees had regular pain in lower back and neck. Almost half of the total bank employees suffered from symptoms like visual stress, headache, fatigue and burning sensations in eye due to prolonged work hours, and insufficient breaks.

KEY WORDS: Computer, Posture musculoskeletal discomfort, Visual stress, Workplace

- HOW TO CITE THIS PAPER : Arya, Neha and Kwatra, Seema (2019). To assess the ergonomic hazards and related musculoskeletal discomfort among bank employees. Asian J. Home Sci., 14 (2) : 261-268, DOI: 10.15740/HAS/AJHS/14.2/261-268. Copyright@ 2019: Hind Agri-Horticultural Society. 